\title{
Malignant pleural mesothelioma in western Glasgow 1980-6
}

\author{
G HULKS, J ST J THOMAS, E WACLAWSKI
}

From the Departments of Respiratory Medicine and Pathology, Western Infirmary, Glasgow, and the Occupational Health Service, Greater Glasgow Health Board

ABSTRACT This study reviews all histologically proved cases of malignant pleural mesothelioma seen in the western district of Glasgow during 1980-6. Sixty eight cases were identified (three female) with an age range at presentation of 48-85 (mean 68.9) years. Asbestos exposure was identified in $54(80 \%)$ of the patients, most of whom had been shipyard workers. Pain and dyspnoea were the most common presenting symptoms. Pleural effusion was found in $57(84 \%)$ of the patients, in a ratio of 2.6 right:left. The median survival was only 30 weeks from the time of presentaton. Prognosis was significantly better for those presenting with dyspnoea than for those with pain (median survival $44 v$ 22 weeks). Postmortem examination was performed in $\mathbf{4 0}$ cases and metastatic disease found in more than three quarters. There was no significant difference between the incidence of the various tumour cell types or any relation between cell type and survival or the incidence of metastatic disease. A substantial increase in cases of malignant pleural mesothelioma has been found in an area of already high incidence. The use of rigorous histological criteria to determine histological cell type has shown that this previously valued variable is of no discriminatory value with regard to disease activity or survival.

\section{Introduction}

Malignant pleural mesothelioma is a relatively uncommon malignancy, with only about 600 cases in Britain each year.' Because of the strong association between mesothelioma and exposure to asbestos, however, certain industrial areas have an unusually high incidence. One such area is the western district of Glasgow by virtue of its proximity to the Clyde shipyards, where asbestos was widely used in the lagging of pipes and boilers. The incidence of mesothelioma was noted to be more than nine times higher in Clydeside than in the rest of Scotland 20 years ago, ${ }^{2}$ and Dorward and Stack reviewed some cases that occurred in this area during the late 1970 s. $^{3}$ We have tried to delineate the developing pattern of disease in an area of high incidence by reviewing all histologically proved cases of mesothelioma that occurred in the western district of Glasgow during 1980-6.

Some of the previous reports that have attempted to relate tumour cell type to disease activity or survival have been based on small numbers ${ }^{45}$ or insufficient biopsy material. ${ }^{6-8}$ These deficiencies are part of the

Address for reprint requests: Dr G Hulks, Department of Respiratory Medicine, Western Infirmary, Glasgow G11 6NT.

Accepted 17 March 1989 reason why there is such conflicting information on the incidence of the various cell types, their propensity to metastatic spread, and the relative prognoses. We have performed postmortem examinations in $\mathbf{4 0}$ cases and related histological cell type to the presence or absence of metastatic disease and to length of survival.

\section{Methods}

Potential cases were identified by scrutinising the reports of all pleural biopsies and postmortem examinations performed at the Western Infirmary, Glasgow, during 1980-6; the catchment population during this time was around 250000 . All material from apparently positive cases was reviewed independently by the pathologist so that prior knowledge of the necropsy diagnosis would not influence interpretation.

Clinical, radiographic, and macroscopic findings were taken into consideration.' Our histological criteria for a diagnosis of mesothelioma were based on previosly published work..$^{11}$ We subtyped our tumours histologically on the basis of the following appearances: (1) a classic biphasic pattern; (2) spindle cell morphology, typical of the sarcomatoid type of malignant mesothelioma; (3) an epithelial pattern in which cytologically appropriate cells were arranged 
either in a typical tubopapillary pattern or in sheets. Because of the potential difficulties in distinguishing these tumours from adenocarcinoma, mucin histochemistry was used routinely and if either the diastase digested periodic acid-Schiff or the Southgate mucicarmine technique ${ }^{12}$ gave significantly positive results the diagnosis was rejected. Where doubt still existed, we stained sections by the cytokeratin antibody CAM 5.2, epithelial membrane antibody, and carcinoembryonic antigen methods, using a standard peroxidase-antiperoxidase technique. Failure to stain with carcinoembryonic antigen was considered strong supportive evidence in favour of mesothelioma. ${ }^{13-15}$ CAM 5.2 and epithelial membrane antibody are epithelial markers that are usually present in both mesotheliomas and pulmonary adenocarcinomas. They are valuable as controls to ensure that technical failure is not responsible for negative staining reaction on a putative mesothelioma, and also as a research tool to allow comparison of our work with previously published data.

For the purposes of histological subtyping, biopsy material alone was considered inadequate. On average five blocks of material from each necropsy were examined as described above and the tumour was subtyped as sarcomatous or epithelial if the relevant patterns occupied $80 \%$ or more of the tumour area. Mixed tumours were so called if these patterns were seen in a lesser ratio. Subtyping was performed by subjective assessment; no formal measurements were made.

Asbestos bodies were sought routinely on standard haematoxylin and eosin stained sections of necropsy material. Where lung smears had been made these were stained by means of the Perls' Prussian blue reaction for iron to aid identification. Specimens were also examined for evidence of a significant desmoplastic reaction in the pleura to infiltrating cells. No attempt was made to quantify this but an area of desmoplasia greater than $25 \%$ of the total tumour area examined was regarded as significant.

Once a mesothelioma had been identified, clinical data were obtained by review of case notes. The significance of clinical and postmortem data in relation to survival was assessed by the log rank test. ${ }^{16}$

\section{Results}

\section{CLINICAL FINDINGS}

Sixty eight cases were identified (three female) and the age at presentation ranged from 48 to 85 (mean 68.9) years. Exposure to asbestos was identified in $54(80 \%)$ of the patients, most of whom had been shipyard workers; the remainder who had been occupationally exposed had been either joiners, plumbers, or insulation workers. Of the 14 cases where asbestos was not identified, four had no occupation recorded in the case
Table 1 Frequency of specific symptoms at presentation among the 68 patients

\begin{tabular}{lc}
\hline & No $(\%)$ \\
\hline Dyspnoea & $46(67)$ \\
Pain & $32(47)$ \\
Cough & $26(38)$ \\
Weight loss $>1$ stone $(6 \cdot 35 \mathrm{~kg})$ & $16(23)$ \\
Hoarseness & $3(4)$ \\
Secondary disease & $1(1)$ \\
Haemoptysis & $1(1)$ \\
(Symptom free) & $6(9)$ \\
\hline
\end{tabular}

Table 2 Methods of histological diagnosis in the 68 patients

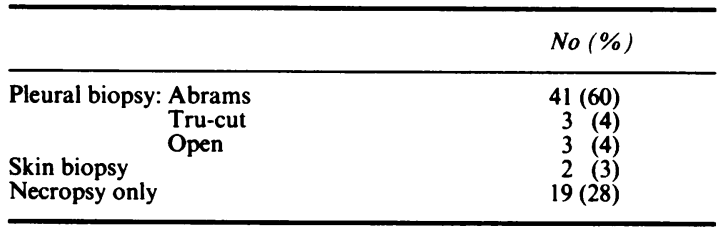

notes. None of the group with no recorded exposure to asbestos had documentation of previous radiotherapy or talc pleuradesis. One man in whom asbestos could not be identified had been a prisoner of war in Japan, working near Nagasaki when the atomic bomb was exploded.

Symptoms at presentation are shown in table 1, dyspnoea and pain being the most common. In some instances the patient was symptom free, a chest radiograph having been taken during the course of investigating some other condition.

Pleural effusion was the most common radiological abnormality, being found in 57 of the 68 patients in a ratio of 2.6 right:left. At the time of diagnosis pleural thickening was seen in only 28 , though ipsilateral fluid may have masked these features before aspiration. Pleural plaques were seen on the films in 13 cases.

Pleural fluid was aspirated from 51 of the 68 patients and in most cases was blood stained. The protein content was that of an exudate with a mean of 46 (range 31-80) g/l. In only three cases were the cells in the fluid thought to be diagnostic of mesothelioma. Histological diagnosis was usually made from pleural tissue obtained by needle biopsy, though other techniques were occasionally used (table 2). In more than a quarter of cases, however, proof was obtained only at necropsy. Only three patients had definitive treatment in the form of radiotherapy or chemotherapy, though 27 underwent aspiration of fluid and pleuradesis with various agents, most commonly bleomycin. Most patients were treated by aspiration and analgesia only. Reaccumulation of fluid was the most common problem, though intractable pain was almost as frequent and more disabling. Tumour was found to track along the site of a previous biopsy or thoracotomy in eight patients. 
SUR VIVAL

The median survival of our patients was 30 weeks from the time of presentation, although the range was considerable (2-247 weeks).

The mode of presentation significantly influenced prognosis (fig 1); those presenting predominantly with pain had a median survival of just 22 weeks (one year survival $4 \%$ ), whereas those with dyspnoea had a median survival of 44 weeks (one year survival $41 \%$ ).

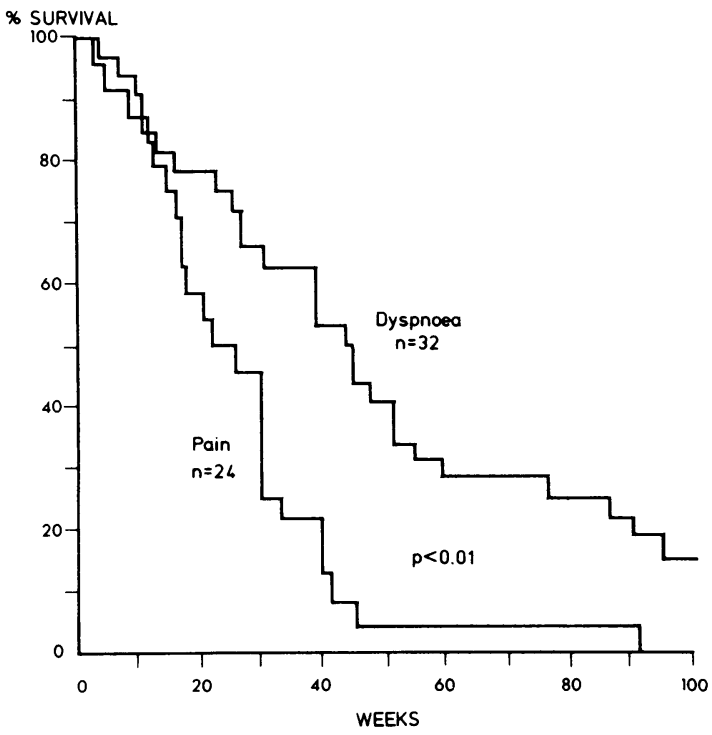

Fig 1 Relation between predominant symptom at diagnosis and survival.

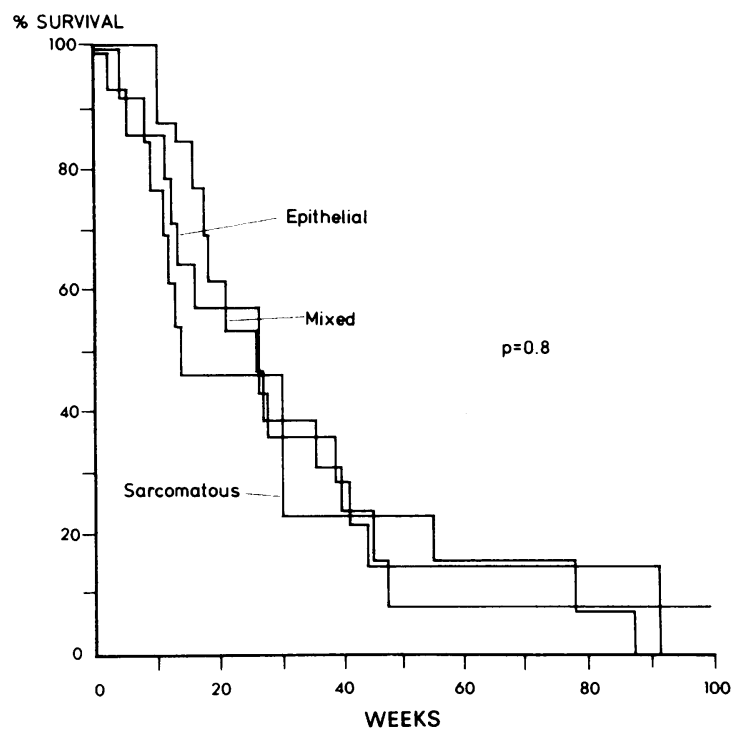

Fig 2 Relation between tumour subtype and survival (14 epithelial, 13 sarcomatous, 13 mixed).
There was no significant difference in survival between those with different tumour subtypes (fig 2).

\section{POSTMORTEM FINDINGS}

Postmortem studies were performed in $\mathbf{4 0}$ of the $\mathbf{6 8}$ cases and asbestos bodies were found in $28(70 \%)$, these being seen more readily in lung sections than in smears. Metastatic disease was found in $54(80 \%)$ of the patients; it was distributed on either side of the diaphragm and even within the cranium (fig 3 ). There was no significant difference in the incidence of the various histological cell types of tumour, or any correlation between cell type and the incidence of metastatic disease (table 3). Significant desmoplastic

Table 3 Histological cell type of mesothelial tumours found at necropsy in 40 cases and incidence of metastatic disease

\begin{tabular}{ll}
\hline & $\begin{array}{l}\text { No }(\%) \text { with } \\
\text { secondary disease }\end{array}$ \\
\hline Sarcomatous $(n=13)$ & $10(77)$ \\
Epithelial $(n=14)$ & $12(85)$ \\
Mixed $(n=13)$ & $10(77)$ \\
\hline
\end{tabular}

Incidence

(\%)

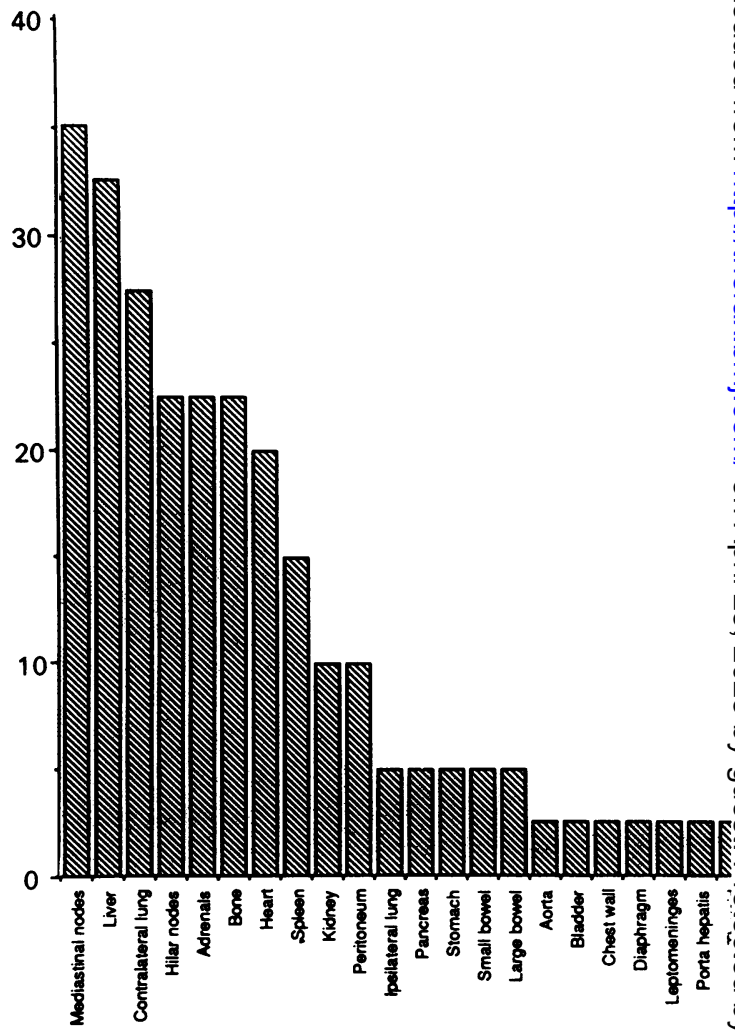

Fig 3 Site of metastatic disease at necropsy in 40 cases. 
reactions were found in six cases at necropsy; three of these were classified as being of mixed type, two sarcomatous, and one epithelial. No difference was noted in the metastatic behaviour of these tumours.

\section{Discussion}

We have found the incidence of malignant pleural mesothelioma to be almost three times higher than that reported in the same population by our colleagues in $1981^{3}$ - that is, $39.5 /$ million population a year. Some of this increase may be accounted for by the fact that the medical and legal professions and the trade unions are now much more aware of the harmful effects of asbestos; but this cannot be the sole explanation and there does seem to have been a genuine increase in incidence, as reported elsewhere. ${ }^{1}$

The fact that asbestos exposure was not identified in $20 \%$ of patients does not necessarily mean that it was not a cause in these cases. Three patients had no occupation recorded in their case notes and in the remainder the occupation recorded was not one usually associated with exposure. These records, however, are usually made by the most junior member of staff; and more experienced clinicians tend to pursue an occupational history rather more aggressively at a later stage, frequently obtaining details of asbestos exposure but not necessarily updating the case notes. In fact, numerous asbestos bodies were seen at necropsy in five of the eight cases in the "exposure negative" group.

Dyspnoea, the most common symptom at presentation, was usually due to an underlying effusion rather than the restrictive effect of pleural thickening, though as the disease progressed massive thickening would often mimic fluid. The right sided preponderance of malignant pleural mesothelioma has been reported in other studies ${ }^{49}$ and attributed to the greater pleural surface; other workers have found no laterality. ${ }^{17} 18$ The poorer prognosis of patients who present predominantly with pain has been reported by one group in the past. ${ }^{1920}$ Pain is usually the result of tumour affecting nerve, bone, or chest wall anc presumably reflects more advanced disease, though the potentially debilitating effect of attempted pain relief (for example, radiotherapy, opiate analgesia) may also accelerate deterioration.

Abrams biopsy provided a histological diagnosis in $41(60 \%)$ of the cases, proving rather more successful than in some previous studies, ${ }^{68917}$ perhaps reflecting the greater familiarity of pathologists with mesothelioma in an area of high incidence. Nevertheless, we considered that neither needle nor open biopsy material was adequate for accurate histological subtyping. Despite the well recognised fact that meso- thelioma may be of different histological types in different areas of the same tumour, ${ }^{21-24}$ many studies have based subtyping on biopsy material, ${ }^{6925-27}$ making definitive claims about the incidence of cell types and their relation to prognosis. Our subtype data are based on multiple blocks of necropsy material, which we believe gives a far more representative picture of the overall histological pattern. Most previous workers have found a preponderance of epithelial tumours, ${ }^{9101728}$ though mixed lesions have predominated elsewhere ${ }^{829}$ and in one study an equal incidence was reported. ${ }^{30}$ The relation of subtypes to prognosis is equally confusing. Some workers have suggested that epithelial ${ }^{2526293132}$ or sarcomatous ${ }^{72}$ tumours carry a better prognosis, whereas other investigators have found that subtype is unhelpful. ${ }^{630}$ We concur with the last group of studies, being unable to show any significant relation between cell type and survival.

Mesotheliomas were originally thought to have low metastatic potential. ${ }^{23} 33$ This has been challenged by more recent reports ${ }^{28}$ some of which have also suggested that sarcomatous lesions were significantly more likely to metastasise. ${ }^{1034}$ The most recent postmortem study, which found secondary disease in $75-83 \%$ of cases, detected no predeliction for any particular cell type..$^{35}$ Our study is of a comparable size and gave very similar results. It has been suggested that in addition to the three main histological types of mesothelioma a fourth, the desmoplastic type, should be recognised. ${ }^{136}$ This is based on the finding of a small number of tumours, diagnosed and typed by pleural biopsy alone, which seemed to show a propensity to metastasise to bone. " These tumours were regarded as being variants of the sarcomatous type of mesothelioma. If such a variant does exist - and we can find little in the way of diagnostic guidelines to identify these tumours-we would emphasise that the occurrence of substantial areas of desmoplasia seems to be distributed evenly among the three main histological types of tumour and that no unusual pattern of metastatic behaviour was noted.

The present study has reviewed a large number of cases of mesothelioma and their associated clinical features. Of particular importance is the considerable number of cases for which complete, independent necropsy reports are available, and the information this gives on the frequency of histological cell type and its relationship to metastatic disease and survival. Those results that are at variance with the findings of previous studies may be partly explained by the stricter classification criteria that we imposed, though other differences remain unaccounted for. Given the lack of definitive treatment currently available, the mode of presentation would seem to provide a guide to prognosis that is accurate enough for clinical needs, 
without the invasiveness of formal staging procedures. ${ }^{1929}$

We are grateful to Mr D Hole, Cancer Surveillance Unit, Ruchill Hospital, Glasgow, for his willing help with statistical analysis.

\section{References}

1 Jones B, Thomas B. Incidence of mesothelioma in Britain. Lancet 1986;i:1275.

2 Greenberg M, Lloyd Davies TA. Mesothelioma register 1967-68. Br J Indust Med 1974;31:91-104.

3 Dorward AJ, Stack BHR. Diffuse malignant pleural mesothelioma in Glasgow. Br J Dis Chest 1981;75: 397-402.

4 Pillgram-Larsen J, Urdal L, Smith-Meyer R, Birkeland S. Malignant pleural mesothelioma. A clinical review of 19 patients. Scand J Thorac Cardiovasc Surg 1984; 18:69-73.

5 Bindi M, Miracco C, Gotti G, Tucci E, Nardi P, Pirtoli L. Metastatic spread of malignant pleural mesothelioma. International Journal of Radiological Sciences 1985;10:131-6.

6 Chailleux E, Dabouis G, Pioche D, et al. Prognostic factors in diffuse malignant mesothelioma. A study of 167 patients. Chest 1988;93:159-62.

7 McCormack PM, Nagasaki F, Hilaris BS, Martini N. Surgical treatment of pleural mesothelioma. $J$ Thorac Cardiovasc Surg 1982;84:834-40.

8 Krumhaar D, Lange S, Hartmann C, Anhuth D. Followup study of 100 malignant pleural mesotheliomas. Thorac Cardiovasc Surgeon 1985;33:272-5.

9 Adams VI, Unni KK, Muhm JR, Jett JR, Ilstrup DM, Bernatz PE. Diffuse malignant mesothelioma of pleura. Cancer 1986;58:1540-51.

10 Law MR, Hodson ME, Heard BE. Malignant mesothelioma of the pleura: relation between histological type and clinical behaviour. Thorax 1982;37:810-5.

11 Adams VI, Unni KK. Diffuse malignant mesothelioma of the pleura: diagnostic criteria based on an autopsy study. Am J Clin Pathol 1984;82:15-23.

12 Kannerstein M, Churg J, Magner D. Histochemistry in the diagnosis of malignant mesothelioma. Ann Clin Lab Sci 1973;3:207-11.

13 Corson JM, Pinkus G. Mesothelioma; profile of keratin proteins and carcinoembryonic antigen. An immunoperoxidase study of 20 cases and comparison with pulmonary adenocarcinoma. Am J Pathol 1982; 108:80-7.

14 Loosli H, Hurliman J. Immunohistological study of malignant diffuse mesothelioma of the pleura. Histopathology 1984;8:793-803.

15 Otis CN, Carter D, Cole S, Battifora H. Immunohistochemical evaluation of pleural mesothelioma and pulmonary adenocarcinoma. Am J Surg Pathol 1987; 11:445-56.

16 Peto R, Pike MC, Armitage P, et al. Design and analysis of randomized clinical trials requiring prolonged observation of each patient. II Analysis and examples. Br J Cancer 1977;35:1-39.
17 Elmes PC, Simpson MJC. The clinical aspects of mesothelioma. $Q J$ Med 1976;45:427-49.

18 Semb G. Diffuse malignant pleural mesothelioma. A clinical study of 10 fatal cases. Acta Chir Scand 1963;126:78-91.

19 Antman KH, Blum RH, Greenberger JS, Flowerdew G, Sharkin AT, Canellos GP. Multimodality treatment for malignant mesothelioma based on a study of natural history. Am J Med 1980;68:356-62.

20 Antman K, Shemin R, Ryan L, et al. Malignant mesothelioma: prognostic variables in a registry of 180 patients, the Dana-Farber Cancer Institute and Brigham and Women's Hospital experience over two decades, 1965-1985. J Clin Oncol 1988;6:147-53.

21 McCaughey WTE. Primary tumours of the pleura. $J$ Pathol Bacteriol 1958;76:517-29.

22 McCaughey WTE. Criteria for diagnosis of diffuse mesothelial tumours. Ann N Y Acad Sci 1965;132: 603-22.

23 Hourihane D O'B. The pathology of mesotheliomata and an analysis of their association with asbestos exposure. Thorax 1964;19:268-78.

24 Whitwell F, Rawcliffe RN. Diffuse malignant pleural mesothelioma and asbestos exposure. Thorax 1971; 26:6-22.

25 Brenner J, Sordillo PP, Magill GB, Colbey RB. Malignant mesothelioma of the pleura. Review of 123 patients. Cancer 1982;49:2431-5.

26 Chahinian AP, Pajak TF, Holland JF, Norton L, Ambinder RM, Mandel EM. Diffuse malignant mesothelioma: Prospective evaluation of 69 patients. Ann Intern Med 1982;96:746-55.

27 Wanebo HJ, Martini N, Melamed MR, Hilaris B, Beattie EJ Jr. Pleural mesothelioma. Cancer 1976;38:2481-8.

28 Roberts GH. Distant visceral metastases in pleural mesothelioma. Br J Dis Chest 1976;70:246-50.

29 Butchart EG, Ashcroft T, Barnsley WC, Hodden MP. Pleuropneumonectomy in the management of diffuse malignant mesothelioma of the pleura: experience with 29 patients. Thorax 1976;31:15-24.

30 Law MR, Gregor A, Hodson ME, Bloom HJG, TurnerWarwick M. Malignant mesothelioma of the pleura: a study of 52 treated and 64 untreated patients. Thorax 1984;39:255-9.

31 Hillerdal G. Malignant mesothelioma 1982: review of 4710 published cases. Br J Dis Chest 1983;77:321-43.

32 Griffiths MH, Riddell RJ, Xipell JM. Malignant mesothelioma: A review of 35 cases with diagnosis and prognosis. Pathology 1980;12:591-603.

33 Churg J, Rosen SH, Moolten S. Histological characteristics of mesothelioma associated with asbestos. Ann NY Acad Sci 1965;132:614-22.

34 Harrison RN. Sarcomatous pleural mesothelioma and cerebral metastases; case report and review of eight cases. Eur J Respir Dis 1982;65:185-8.

35 Huncharek M, Muscat J. Metastases in diffuse pleural mesothelioma: influence of histological type. Thorax 1987;42:897-8.

36 Machin T, Mashiyama ET, Henderson JAM, McCaughey WTE. Bony metastases in desmoplastic pleural mesothelioma. Thorax 1988;43:155-6. 